\title{
Gökkuşağı Alabalığında (Oncorhynchus mykiss) Ovaryum Sıvısının Sperm Motilite Parametreleri ve Döllenme Üzerindeki Etkisi
}

\section{Güneş YAMANER}

İstanbul Üniversitesi Su Bilimleri Fakültesi, Su Ürünleri Yetiştiriciliği ve Hastalıkları Bölümü, İstanbul, Türkiye

*Sorumlu Yazar: gyamaner@istanbul.edu.tr

Araştırma Makalesi

Geliş 16 Aralık 2019; Kabul 27 Nisan 2020; Basım 01 Haziran 2020.

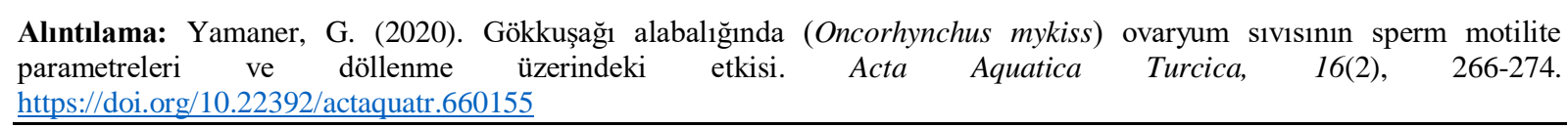

Özet

Bu çalışmada, Gökkuşağı alabalığında (Oncorhynchus mykiss) sperm aktivasyonunda aktivasyon solüsyonu olarak kuluçkahane suyuna ilaveten ovaryum sıvısının kullanılmasının motilite (\%) ve eğrisel hız (VCl, $\mu \mathrm{m} / \mathrm{saniye})$ üzerindeki etkisi ve ovaryum sıvısı uzaklaştırılmış yumurta örneklerinde döllenme yüzdesi araştırılmıştır. Çalışmada üreme döneminde $3^{+}$yaş grubuna ait üç adet dişi ve altı adet erkek balık kullanılmışıı. Her bir dişe bireye ait yumurta örneklerinde, analizi yapılan sperm örnekleri ile hem ovaryum sıvısı muhafaza edilerek hem de uzaklaștırılarak dölleme gerçekleștirilmiştir. Sperm örneklerine ait motilite (\%) değerlerinde kuluçka suyu kullanılarak aktive edilmiş örnekler ile ovaryum sıvısı kullanılarak elde edilmiş örnekler arasındaki sonuçlar istatiksel olarak farklı bulunmuşken $(p<0.05)$; motiliteye ait kinematik parametreler arasındaki fark önemsiz bulunmuştur $(\mathrm{p}>0.05)$. Dölleme grupları arasında ise döllenme yüzdesinde herhangi bir fark bulunmamıştır.

Anahtar Kelimeler: Ovaryum sıvısı, Motilite parametreleri, Gökkuşağı Alabalığı, Döllenme Yüzdesi

The Effect of Ovarian Fluid on Motility Characteristics and Fertilization Ratio of Rainbow Trout (Onchorhynchus mykiss) Sperm

\begin{abstract}
In this study, the effect of ovarian fluid and hatchery water as activation solutions for sperm activation in rainbow trout (Oncorhynchus mykiss) on motility $(\%)$ curvilinear velocity $(\mathrm{VCl}, \mu \mathrm{m} / \mathrm{sec}$ ) and fertilization rate were analyzed. Three female and six male fish belonging to the $3^{+}$age group were used in the study. Each females' egg was fertilized with analyzed sperm samples both either removing ovarian fluid or not. Between results of the motility (\%) values of sperm samples that activated with hatchery water and ovarian fluid were found statistically different $(p<0.05)$; the difference between the kinematic parameters of motility was insignificant $(p>0.05)$ among group. There was no difference between the fertilization rate in the groups.
\end{abstract}

Keywords: Ovarian fluid, Motility Characteristics, Rainbow trout, fertilization rate

\section{GİRIŞ}

Spermatozoa motilitesi ve spermatozoaya ait hız parametreleri, erkek bireylerin sahip olduğu üreme başarısının belirlenmesinde ve bu bireylerin gamet kalitesinin ortaya konmasında kullanılan iki önemli parametredir. Yüksek motiliteye ve hıza sahip olan spermatozoa'nın mikrofil deliğine daha kısa zamanda ulaşması, bu sperm hücrelerinin, "Dölleme Yeteneği Yüksek" başka bir deyişle "Kaliteli Sperm" olarak sınıflandırılmasını sağlamaktadır. Sperm motilitesinin analizi dış döllenme özelliğine sahip, gametlerini su ya da benzeri solüsyon içerisine bırakan türlerde özellikle önem arz etmektedir (Kime vd., 2001; Cosson, 2004) ve spermatozoonların bu su içerisinde mikrofil açıklığına doğru hareketini belirlemede kullanılan bu analiz, döllenme sürecinde kritiktir (Cosson vd., 2008; 2010).

Birçok Teleost balık türünde olduğu gibi Salmonid balık türlerinde de spermatozoa testiste ve seminal plazma içerisinde hareketsiz bir haldedir. Salmonid balıklarda spermatozoa'nın immotile halde kalmasının ilk nedeni seminal plazmanın ihtiva ettiği Potasyum $\left(\mathrm{K}^{+}\right)$iyonudur. Su ya da yapay olarak hazırlanmış aktivasyon solüsyonunun içerisine bırakılan spermatozoa, seminal plazma'nın $\mathrm{K}^{+}$ iyonundaki değişim ile motil hale geçerler başka bir deyişle hareketlilik kazanırlar. Salmonid balıklarda $\mathrm{K}^{+}$iyonunun spermatozoa motilitesini inhibe edici bu özelliğine ilaveten, dişi balıklarda 
ovaryum sıvısının ihtiva ettiği Sodyum $\left(\mathrm{Na}^{+}\right)$ve Kalsiyum gibi $\left(\mathrm{Ca}^{2+}\right)$ katyonyaların konsantrasyonlarıda sperm motilitesini etkiyelebilmektedir (Stoss, 1983; Billard ve Cosson, 1992).

Salmonid balıklarda ovaryum sivis1 toplam yumurta hacminin \%10-30 oranında bir hacime sahiptir ve yumurtaların birakılması ile su ortamına birakılmaktadır. Ovaryum sivisı kan plazmasinın filtrasyonu ve ovaryuma ait epitel dokunun salgı aktivitesi sonucu oluşmaktadır ve çeşitli yap1 maddelerini, metabolitleri ve hormonları içermektedir (Hirano vd., 1978; Lahnsteiner vd., 1995; Zadmajid vd., 2019). Ovaryum sıvısının sperm motilitesini başlatmak ve arttırmak başta olmak üzere, döllenme yüzdesini arttırmak, feromon özellikler, cinsiyet steroidlerini artırmak ve yumurtaları korumak gibi özellikleri vardır (Lahnsteiner, 2002; Johnson vd., 2004). Bununla birlikte ovaryum sıvısının spermatozoa yaşam süresini arttırdığı (Lahnsteiner vd., 1995; Dietrich vd., 2008) ve spermatozoa kinematik parametrelerinden hız, yön ve hareket şekli gibi parametreleri etkilediği de bilinmektedir (Lahnsteiner vd., 1995). Yapılan çalışmalar ile ovaryum sıvısının döllenme ortamında bulunmasının spermatozoonların yaşam süresini arttırdığı Tatlı su balıklarından Dere iskorpit balığı (Cottus gobio) (Lahnsteiner vd., 1997) ve Kahverengi alabalık (Salmo trutta f.fario) gibi türlerde ortaya konmuştur (Lahnsteiner, 2002). Salvelinus alpinus (Turner ve Montgomeria, 2002; Dietrich vd., 2008); Atlantik morinas1 (Gadus morhua) (Litvak ve Trippel, 1998) gibi türlerde spermatozoa aktivasyonu için ovaryum sıvısının kullanılmasının; tatlı su, deniz suyu ya da yapay aktivasyon solüsyonlarının kullanıldığı durumlar ile karşılaştırılmasında, spermatozoa hız parametrelerinde ve motilite süresinde artış ile sonuçlandığı bulunmuştur. Bu çalışmaların aksine Spinachia spinachia (Elofsson vd., 2003) ve Kızıl Somon Balığı (Oncorhynchus nerka) (Macfarlane, 2002) gibi türlerde ovaryum sıvısının sperm yaşam süresi üzerinde arttırıcı bir etkisinin olmadığını ifade eden çalışmalarda mevcuttur. Ovaryum sıvısının kimyasal ve fiziksel yapısı balık türleri arasında olduğu gibi tür içerisinde de farklılık göstermektedir ve döllenme esnasında her bir dişi balık üreme dönemi sürecinde kendine özgü bir döllenme ortamı yaratır (Lahnsteiner, 2002). Ovaryum sıvısının, spermin ortama bırakılmasından sonra, yumurta ve spermatozoa arasındaki etkileşimi başlattığı, dispersiyonu düşürdüğü ve döllenme için gerekli olan mikro-çevre ortamını sağlayan iyon konsantrasyonunu koruduğu bilinmektedir (Lahnsteiner, 2002; Rosengrave vd., 2009). Tüm bu aşamalarda, ovaryum sıvısının tür içerisinde her bir dişide farklı kimyasal ve fiziksel özellikte olması, spermatozoa üzerindeki farklı etkilerini de açıklamaktadır. Aynı zamanda bu kimyasal ve fiziksel özellikler, spermatozoa' da motilite başlar başlamaz, ortamdaki yumurta ve ovaryum sıvısının varlığı ile sperm hücrelerinin yumurtaya doğru hareket etmeye başlamasını sağlamaktadır ve bu "Kemotaksi" olarak bilinmektedir (Morisawa ve Yoshida, 2005). Litvak (Litvak ve Trippel, 1998) ve Rakitin (Rakitin vd., 1999a,b) yapmış olduğu çalışmada erkek bireyin dölleme başarısının farklılı̆̆ını; farklı dişilere ait ovaryum sıvılarının farklı kimyasal özelliklerinden kaynaklandığı ifade etmektedir.

Dölleme esnasında kullanılan su ya da benzeri aktivasyon solüsyonları spermatozoaaktivasyonunu sağlamasının yanı sıra yumurtanın dölleme sonrasında mikrofil açıklığının kapanmasını da sağlamaktadır (Lahnsteiner, 2002). Döllenmeyi ve gamet fizyolojisini büyük oranda etkileyen bu solüsyon bu güne kadar birçok balık türünde çalışılmış ve günümüze kadar yapılan çalışmalar ile her bir tür için optimal aktivasyon solüsyonu ortaya konmuştur (Zadmajid vd., 2019). Bu çalışmada ise, yapay bir aktivasyon solüsyonu kullanılmamış; ovaryum sıvısı ve kuluçkahane suyu ile sperm motilite analizleri yapılarak, analizi yapılan örnekler ile dölleme çalışması gerçekleştirilmiştir. Bu çalışmanın amacını Gökkuşağı alabalığında ovaryum sıvısının motilite ve döllenme üzerindeki etkisini ortaya koymak oluşturmaktadır. Ovaryum sıvısının spermatozoa motilitesi üzerindeki etkisinin incelenmesine ilaveten; bu etkinin döllenme ile ilişkisinin ortaya konması amaçlanmıştır.

\section{MATERYAL ve YÖNTEM}

\section{Çalışmada kullanılan balıklar}

Çalışmada İstanbul Üniversitesi Su Bilimleri Fakültesi Sapanca İçsu Ürünleri Araştırma ve Uygulama Biriminde bulunan, birimin Rutin üretim çalışmalarında kullandığı Gökkuşağı alabalığ (Oncorhyncus mykiss) anaç balıkları kullanılmıştır. $3^{+}$yaş grubunda üç adet dişi Gökkuşağı alabalığ ve $3^{+}$yaş grubunda altı adet erkek Gökkuşağı alabalığ işlemine tabii tutulmuşlardır.

\section{Balıkların sağım işlemi}

Bulundukları tanklardan Anestezi tankına alınan balıklar, bayıltıldıktan sonra sağım işlemi gerçekleştirilmiştir. Anestezi maddesi olarak Phenoxyethanol (385 mg/l) kullanılmıştır (Steinum ve 
Candan, 2010). Abdomen bölgesi kurulanan dişi balıklar kuru sağım kaplarına; erkek balıklar ise kuru cam beherlere sağılmıştır. Örnekler analiz çalışmasına kadar $+4{ }^{\circ} \mathrm{C}$ 'de strafor kutu içerisinde muhafaza edilmişlerdir.

\section{Fekonditenin belirlenmesi}

Dişi balıklardan alınan yumurtalarda her bir dişi balık için alt örnekleme yöntemi ile fekondite belirlenmiştir. Her bir dişiden alınan yumurta örneği tartılarak, tartılan gramajdaki yumurta sayısı hesaplanmıştır. Fekondite hesabında aşağıdaki formül kullanılmıştır.

$\Sigma$ Fekondite $($ adet $/ \Sigma \mathrm{kg})=$ Alt örnek yumurta sayısı (adet) $* \Sigma$ Yumurta ağırlığı (gr)/Alt örnek ağırlık (gr) (Hunter vd., 1985).

\section{Spermatolojik özelliklerin belirlenmesi}

Her bir erkek balıktan alınan sperm örneklerinde spermatolojik özelliklerden spermatozoa motilitesi (\%) ve spermatozoaya ait hareket özelliklerinden eğrisel hız (VCL, $\mu \mathrm{m} / \mathrm{sn}$ ), Bilgisayarlı Otomatik Sperm analiz Sistemi ile ölçülmüştür. Bahsi geçen sistemde normal lam kullanılmayıp, özel bölmeli ve hacimli lam kullanıldığından, mikropipet yardımı ile alınan sperm örnekleri ependorf tüpe aktarılmış ve üzerine aktivasyon solüsyonu eklenmiştir. Sulandırma oranı olarak 1:500 (sperm: sulandırıcı) oranı kullanılmıştır. Çalışmada aktivasyon solüsyonu olarak iki farklı solüsyon kullanılmıştır. Anaç balıkların bakımının yapıldığı su kaynağı ilk aktivasyon solüsyonu olarak; dişi balıkların sağımı esnasında temin edilen her bir dişiye ait ovaryum sıvısı ise ikinci aktivasyon solüsyonu olarak belirlenmiş̧ir. Aktivasyon solüsyonunun eklenmesinden hemen ardından, karışımdan alınan sulandırılmış örnek lama ait özel bölmeye konulmuştur. Analiz için hazırlanmış lam örneği sistemin parçalarından biri olan mikroskoba yerleştirilmiştir. Mikroskoba bağlı bulunan kamera sistemi ile spermatozoonların hareketinin 10.saniyesinde motilite ve motiliteye bağlı kinematik parametreler kaydedilmiştir. Her bir sperm örneği için 3 video analizi 3 tekerrürlü olarak yapılmıştır. CASA sistemi kaydedilen video görüntülerini kayıttan sonra analiz yapmaya olanak verdiğinden; tüm örneklerin hareketliliğinin mikroskop altında kaydedilmesinden sonra, depolanan veriler yine sistem parçalarından birini oluşturan, motilite ve motiliteye ait kinematik hız parametrelerinin analizini otomatik olarak yapan yazılım sistemi (Hamilton) ile belirlenmiştir (Boryshpolets vd., 2013; Özgür vd., 2019).

\section{Deneme grupları ve dölleme çalışması}

Her bir dişi balıktan alınan toplam yumurta gramajı hesaplandıktan sonra, yumurtalar ile birlikte bulunan ovaryum sıvısı temiz bir süzgeç yardımı ile uzaklaştııılarak temiz başka bir kaba aktarılmıştır. Ovaryum sıvısız kalan toplam yumurtalar, eşit gramajda iki kısıma ayrılmıştır. Bir kısım yumurtanın üzerine, daha önce ayrılmış ovaryum sıvısı eklenirken; diğer kısım yumurta ovaryum sıvısız halde bırakılmıştır. Her bir dişinden ovaryum sıvılı ve ovaryum sıvısız olmak üzere iki kısma ayrılan yumurtalar, spermatolojik özellikleri belirlenmiş iki adet erkek bireye ait spermler ile pooling yapılarak döllenmiştir. Dölleme esnasında biriminin rutin dölleme çalışmalarında ki prosedür izlenmiş herhangi bir modifikasyon yapılmamıştır (Çelikkale, 2002). Her bir dişi balık için iki adet olmak üzere toplam altı adet farklı erkek birey kullanılmıştır. Dölleme esnasında aktivasyon ve dölleme solüsyonu olarak, balıkların içerisinde bulunduğu tankı besleyen ve spermatolojik özelliklerin belirlenmesinde aktivasyon solüsyonu olarak kullanılan su kaynağı kullanılmıştır.

Dölleme işleminden sonra döllenmiş yumurtalar, birim kuluçkahanesine ait işaretlenmiş basket inkübatör sistemlerine her bir grup bir baskette olacak şekilde yerleştirilmişlerdir. Günlük olarak ölü yumurtalar sifonlama yöntemi ile temizlenmiş ve gruplara ait mortalite kaydedilmiştir. Döllenme yüzdesi gözlü evre aşamasına kadar belirlenmiştir ve aşağıdaki formülasyon kullanılmıştır.

Döllenme yüzdesi $(\%)=\Sigma$ Döllenmiş yumurta sayıs1 $/ \Sigma$ Yumurta sayıs $* 100$

\section{İstatistiksel analizler}

Deneme sonunda elde edilen veriler ortalama değerleri ve standart sapmaları ile birlikte sunulmuştur. Elde edilen veriler STATISTICA v.8 programı yardımı ile bağımsız t-testi kullanılarak değerlendirilmiştir (Zar, 1996).

\section{BULGULAR}

Çalışmada üç dişi bireyden ortalama $7115 \pm 699$ adet yumurta alınmıştır. Çalışmada kullanılan her bir dişi balıkta hesaplanan toplam fekondite miktarları ve her bir dişi balığa ait dölleme çalışmasında kullanılan yumurta adetleri Tablo 1'de verilmiştir. 
Tablo 1. Dişi bireylere ait toplam fekondite miktarları ve dölleme çalışmasında kullanılan yumurta sayıları

\begin{tabular}{cccc} 
Birey & $\boldsymbol{\Sigma}$ Fekondite (adet) & $\begin{array}{c}\text { Ovaryum sivilı döllenen } \\
\text { yumurta sayısı (adet) }\end{array}$ & $\begin{array}{c}\text { Ovaryum sivisız döllenen } \\
\text { yumurta sayısı (adet) }\end{array}$ \\
\hline 1 & 7911 & 3955 & 3956 \\
2 & 6835 & 3417 & 3418 \\
3 & 6600 & 3300 & 3300 \\
\hline \hline
\end{tabular}

Çalışmada kullanılan erkek balıklardan elde edilen sperm örneklerinde analiz edilen spermatolojik parametreler ve ortalama sonuçları Tablo 2'de gösterilmiştir.

Tablo 2. Ovaryum sıvısı ve Kuluçkahane suyu kullanılarak aktive edilen Sperm örneklerinde motilite $(\%)$, ve VCL $(\mu \mathrm{m} / \mathrm{s})(\mathrm{Ort} \pm \mathrm{sd})$

\section{Parametreler}

\begin{tabular}{cccc} 
Birey (n:2) & Aktivasyon solüsyonu & Motilite $(\boldsymbol{\%})$ & VCL $(\boldsymbol{\mu m} / \mathbf{s})$ \\
\hline \multirow{2}{*}{1} & Kuluçka suyu & $56,1 \pm 1,8$ & $94 \pm 1$ \\
& Ovaryum sıvısı & $93,3 \pm 1,1$ & $96 \pm 0,5$ \\
2 & Kuluçka suyu & $52 \pm 0,7$ & $76 \pm 2,7$ \\
\multirow{2}{*}{3} & Ovaryum sıvıs1 & $78,4 \pm 0,8$ & $75,1 \pm 4$ \\
& Kuluçka suyu & $61 \pm 0,4$ & $100 \pm 4,5$ \\
\hline \hline
\end{tabular}

Kuluçka suyu ile aktivasyonda elde edilen spermatozoa motilite yüzdeleri, ovaryum sıvısı ile elde edilen yüzdelerden daha düşük bulunmuştur. Pooling yapılan spermlerde kuluçka suyu ile aktivasyonda spermatozoa motiliteleri suras1 ile ilk grupta $\% 56,1 \pm 1,8$; ikinci grupta $\% 52 \pm 0,7$ ve üçüncü grupta \%61 00,4 olarak hesaplamıştır. Aynı sperm örnekleri ovaryum sıvısı ile aktive edildiğinde ise elde edilen motilite sonuçları sırası ile \%93,3 $\pm 1,1 ; 78,4 \pm 0,8$ ve $\% 96,3 \pm 0,9$ olarak bulunmuştur (Tablo 2). Aktivasyon solüsyonu olarak kuluçka suyu ve ovaryum sıvısı kullanılan bu örneklerde, elde edilen motilite sonuçları istatiksel olarak karşılaştırıldığında iki aktivasyon solüsyonu ile elde edilen motilite sonuçları arasında anlamlı bir fark olduğu tespit edilmiştir $(p<0,05)$ (Şekil 1). 


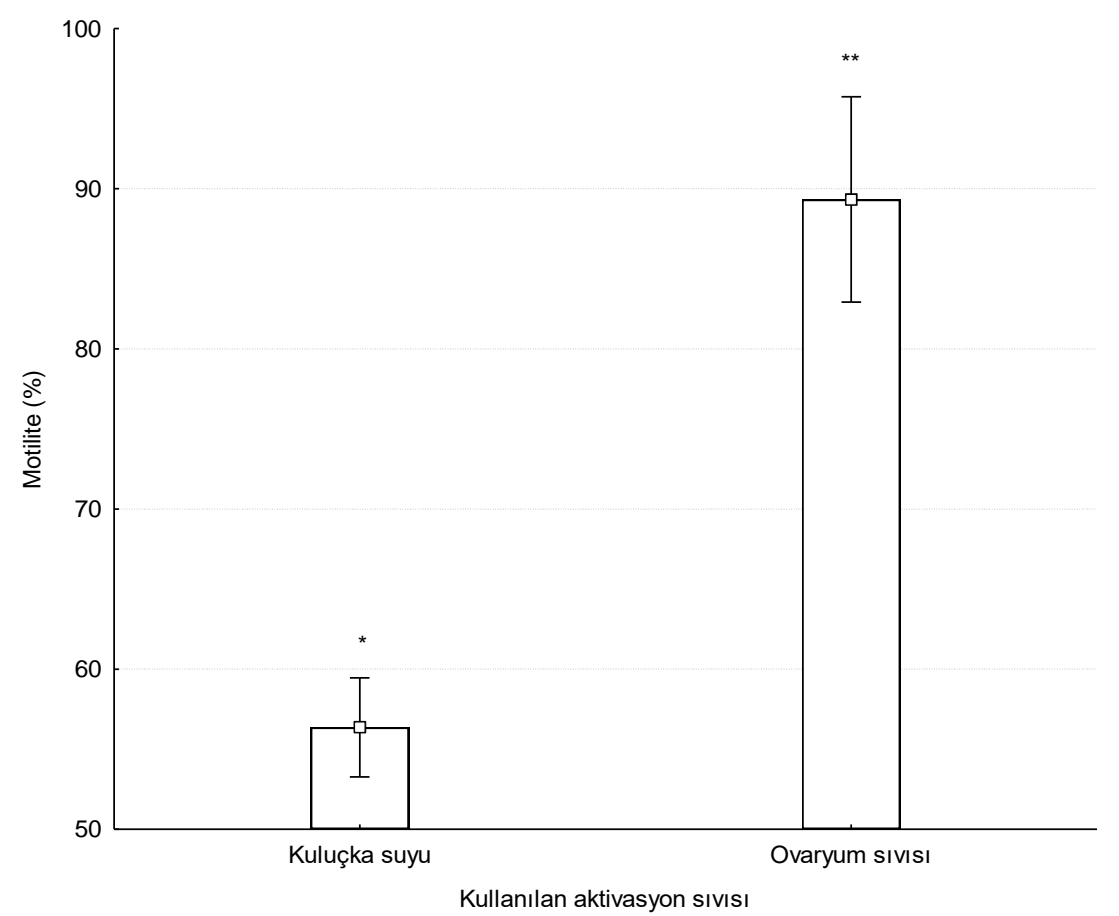

Şekil 1. Sperm örneklerinde kuluçka suyu ve ovaryum sıvısı kullanılarak elde edilen ortalama motilite (\%) değerleri. Grafiklerde değerler Ortalama \pm SD olarak verilmiştir. * değerler arasındaki istatistiksel farkı göstermektedir $(\mathrm{p}<0,05)$.

En yüksek olarak üçüncü deneme grubunda hem kuluçka suyu $(100 \pm 4,5 \mu \mathrm{m} / \mathrm{sn})$ hem de ovaryum sıvisı kullanılarak elde edilen motilite VCL değeri $(102,3 \pm 3 \mu \mathrm{m} / \mathrm{sn})$ sırası ile birinci deneme grubunda kuluçka suyu için $94 \pm 1 \mu \mathrm{m} / \mathrm{sn}$; ovaryum sıvısı için ise $96 \pm 0,5 \mu \mathrm{m} / \mathrm{sn}$ olarak; ikinci deneme grubunda ise kuluçka suyu için $76 \pm 2,7 \mu \mathrm{m} / \mathrm{sn}$; ovaryum sıvısı için ise $75,1 \pm 4 \mu \mathrm{m} / \mathrm{sn}$ olarak tespit edilmiştir. Eğrisel hız sonuçlarında her iki parametreye ait sonuçlar her iki solüsyonda da elde edilen sonuçlar ile benzer bulunmuş ve aralarında istatiksel olarak anlamlı bir fark tespit edilmemiştir (Şekil 2).

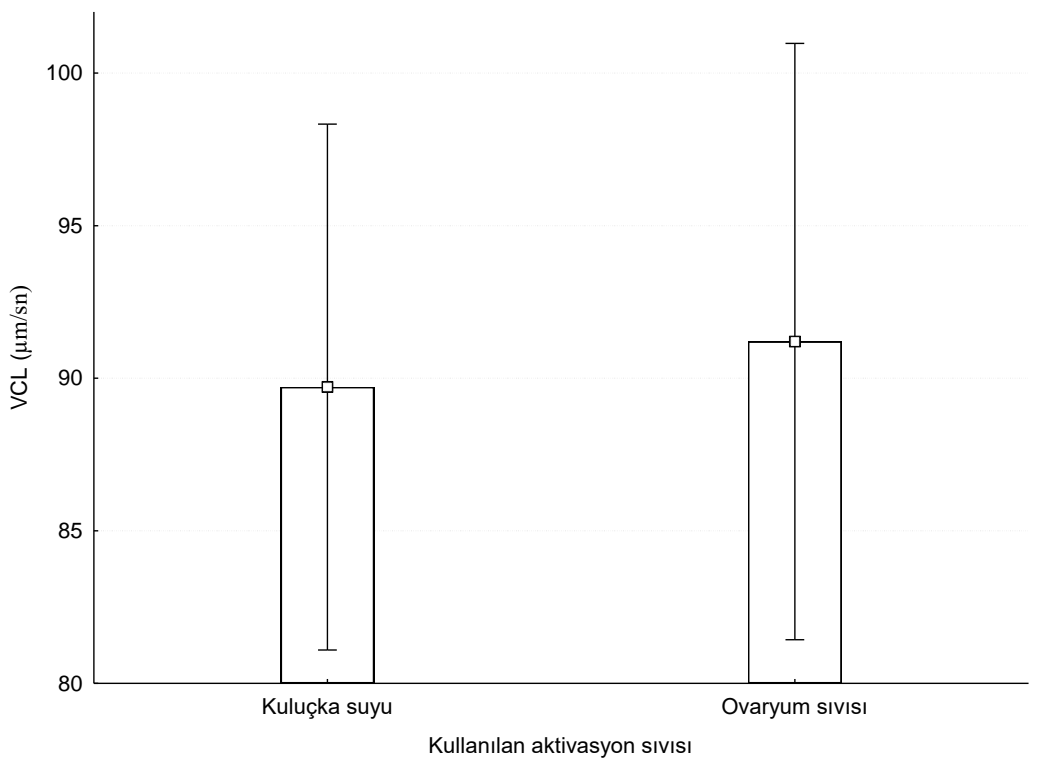

Şekil 2. Sperm örneklerinde kuluçka suyu ve ovaryum sıvısı (OS) kullanılarak elde edilen VCL ( $\mu \mathrm{m} / \mathrm{sn})$ değerleri. Grafiklerde değerler Ortalama \pm SD olarak verilmiştir. 
Ovaryum sıvısı ile ve ovaryum sıvısı uzaklaştırılarak yapılan dölleme çalışması sonucunda, elde edilen döllenme yüzdeleri Şekil 3' de gösterilmiştir. Tüm yumurta gruplarında döllenme görülmüşken; ovaryum sıvısının uzaklaştırıldığı gruplarda döllenme yüzdeleri ovaryum sıvılı dölleme sonuçlarına göre daha düşük bulunmuştur.

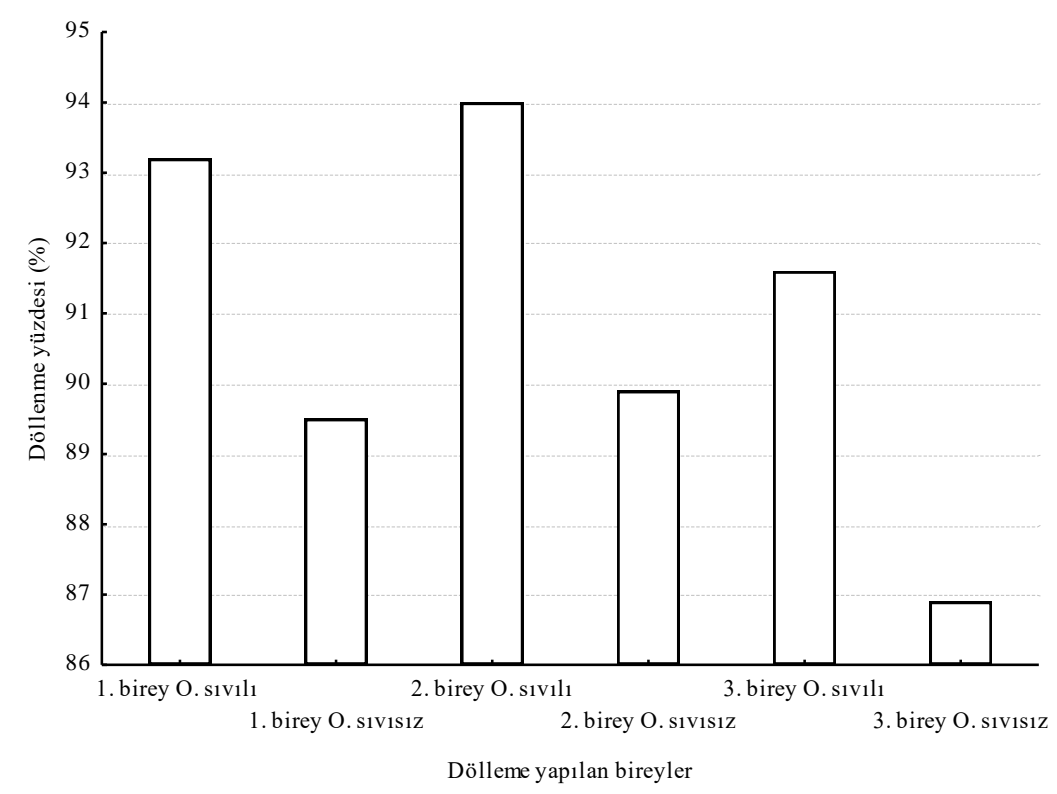

Şekil 3. Deneme gruplarında döllenme yüzdeleri

\section{TARTISMA ve SONUC}

Ovarian epitel hücrelerinden oluşmuş ovaryum sıvısı organik (protein, serbest aminoasitler, glikoz, fosfolipitler, kolesterol ve çeşitli enzimler) ve inorganik maddeleri $\left(\mathrm{Na}^{+}, \mathrm{Ca}^{2+}\right.$, osmolarite ve $\left.\mathrm{pH}\right)$ ihtiva etmektedir ve dış döllenme özelliğine sahip salmonid balıklarda yumurta ile birlikte vücuttan dışarı atılmaktadır (Lahnsteiner, 2002). Ovulasyonun son ermesi ile döllenme yeteneği kazanmış olan yumurtalar vücut boşluğuna dökülür ve vücuttan dışarı atılana kadar yarı yapışkan olan ovaryum sıvısının içinde muhafaza edilir (Lahnsteiner, 2002). Ovaryum sıvısının bu organik ve inorganik yapısı ve varlı̆̆ inseminasyon aşamasında gametlerin bulunduğu çevreyi etkilediği kadar; sperm/yumurta (kemotaksi) etkileşimi üzerinde de etkilidir (Barrannikova vd., 2002; Bayunova vd., 2003).

Sperm motilitesi sperm kalitesinin belirlenmesinde ve döllenme yüzdesinin başarısında kullanılan parametrelerden biri (Lahnsteiner vd., 1998; Golpour vd., 2013) ve ovaryum sivisının direk olarak etkilediği, dölleme başarısını belirleyici faktörlerdendir. Ovaryum sıvısının yumurtaları ve yumurtaların döllenme yeteneğini korumasının yanı sıra, döllenmedeki diğer etken olan spermatozoa motilitesi ve motilite parametreleri üzerindeki etkisi de yapılan çalışmalar ile ortaya konmuştur. Dil balığı (Solea selanegansis) ile yapılan çalışmada; ovaryum sıvısı ile aktivasyonun sağlandığı sperm örneklerinde elde edilen değerler, yapay aktivasyon solüsyonu ile elde edilen değerlerden çok daha yüksek bulunmuştur (Diogo vd., 2010). Gökkuşağı alabalığında (Oncorhynchus mykiss) (Yoshida, 1972; Dietrich vd., 2008); Göl alabalığında (Salvelinus namaycush) (Galvano vd., 2013); Kafkas alabalı̆̆ında (Salmo trutta caspius) (Hatef vd., 2009); Kral somon balı̆̆ında ( Oncorhynchus tshawytscha) (Rosengrave vd., 2009) ve Alp alabalığında (Salvelinus alpinus) (Turner ve Montgomerie, 2002) kuluçkahane suyu ya da aktivasyon solüsyonları ile elde edilen motilite değerleri; ovaryum sıvısı ile elde edilen motilite değerlerinden çok daha düşük bulunmuş ve ovaryum sıvısının motiliteyi arttıcı etkisi ortaya konmuştur. Hatef vd., (2009) Kafkas alabalığı ile yapmış olduğu çalışmada spermatozoa aktivasyonu için tatlı su, deniz suyu ve ovaryum sıvısını kullanmış ve sperm motilitesine ilaveten en yüksek döllenme yüzdesini deniz suyu ve ovaryum sıvısı kullandığı gruplarda bulmuştur. Yazar bir tatlı su balığı olmasına rağmen, bu türün sperm aktivasyonunda deniz suyunun daha iyi sonuç vermesini deniz suyunun ve ovaryum sıvısının benzer oranda $\mathrm{Na}^{+}$içermesi ve tuzun motilite süresini uzatması sebebi ile olduğunu açıklamıştır. Ovaryum sıvısının varlığı ve motilite arttırıcı etkisi deniz balıklarında da çalışılmış (Dil balığı); aktivasyon solüsyonu olarak sadece deniz suyunun kullanıldığı örneklerde motilite sağlanamamışken; ovaryum sıvısının eklenmesi ile bu 
örneklerde motilite görülmüştür (Alonzo vd., 2016; Diogo vd., 2010; Litvak vd., 1998). Döllemede etkin rol oynayan spermatozoa hızı da, sperm motilitesine benzer bir şekilde ovaryum sıvısının kullanılması durumunda diğer aktivasyon solüsyonlarına göre artış göstermiş ve bu durum göl alabalı̆̆ında (Butts vd., 2012), gökkuşağı alabalığında (Dietrich vd., 2008) kral somon balığı (Rosengrave vd., 2009; 2016) ve Alp alabalığında (Turner ve Montgomerie, 2002) yapılan çalışmalar ile ortaya konmuştur. Yine kral somon balığında yapılan bir çalışmada spermatozoa aktivasyonunun ovaryum sıvısı ile yapıldığı her durumda spermatozoaya ait tüm kinematik parametrelerin arttığ bildirilmiştir (Butts vd., 2017). Bu çalışmada sperm motilitesinin ovaryum sıvısı ile artış gösterdiği bulunmuştur. Sperm örneklerinde ovaryum sıvısı ile aktivasyon sonrasında elde edilen motilite değeri $78-96 \%$ arasında değişiklik göstermiş ve bu sonuçlar kuluçka suyu ile aktive edilerek elde edilen değerlerden (\%52-61) daha yüksek bulunmuştur.

Ovaryum sıvısının inorganik ve organik yapısı motilite kadar döllemede diğer bir sperm kalitesi parametresi olan spermatozoa hızları üzerinde de etkilidir. Atlantik morinası (Gadus morhua) (Litvak ve Trippel, 1998), Gökkuşağı alabalığı (Wojtczak vd., 2007; Dietrich vd., 2008) ve Alp alabalığında (Turner ve Montgomerie, 2002; Urbach vd., 2005) yapılan çalışmalarda yapay olarak hazırlanmış aktivasyon solüsyonlarında elde edilen sperm motilitesine ait hız değerleri; ovaryum sıvısı ilave edilen aktivasyon solüsyonlarında elde edilen sonuçlardan çok daha düşük bulunmuş ve ovaryum sıvısının hızı arttırıcı etkisi ortaya konmuştur. Son zamanlarda kral somon balığında in vitro olarak yapılan bir çalışmada, ovaryum sıvısı içerisinde en yüksek hıza sahip olan spermatozoa dölleme yüzdesinin diğerlerine göre çok daha yüksek olduğu ve ovaryum sıvısının varlığı ile hazırlanmış bu rekabetçi ortamın spermatozoa hızını arttırması ile sonuçlanmasına ilaveten, spermatozoa hızı ile embriyonun hayatta kalma yüzdesi arasında da bir ilişki olduğu ifade edilmiştir (Lewis ve Pitcher, 2017; Rosengrave vd., 2016). Kral somon balığı ile yapılan başka bir çalışmada ise su ile aktivasyonun sağlanmasında sperm hızı daha düşük olmasına rağmen; döllenme yüzdesinin daha yüksek olduğu bulunmuştur (Lehnert vd., 2017). Aynı çalışmada ovaryum sıvısında aktive olan spermatozoa hızları, aktivasyon solüyonu olarak sadece suyun kullanıldığı deneme gruplarından \%23.7 oranında daha yüksek olarak bildirilmiştir. Bu çalışmada spermatozoaya ait VCL değerlerinde, aktivasyon solüsyonu olarak kuluçkahane suyu ya da ovaryum sıvısı kullanılmasının bir fark yaratmadığı; her iki aktivasyon solüsyonunda sperm hücrelerinin benzer hız değerlere sahip olduğu bulunmuştur.

Ovaryum sıvısı ve spermatozoa motilitesi arasındaki ilişki hakkında yapılan ve ovaryum sıvısının aktivasyon solüsyonu olarak kullanılması esnasında sulandırılması gerektiğini ifade eden çalışmalarda mevcuttur. Wojtczak vd., (2007) salmonid balıklarda ovaryum sivisının \% 50 oranında sulandırılmas1 ile daha yüksek motilite değerinin elde edildiğini bildirmişken; Dil balığında yapılan bir çalışmada $\% 25$ oranında sulandırmanın en iyi değerleri verdiği ortaya konmuştur (Diogo vd., 2010). Bu çalışmada ovaryum sıvısı herhangi bir sulandırmaya tabii tutulmamıştır (\% 100) ve elde edilen motilite değerleri değerlendirildiğinde ovaryum sıvısının \%100 kullanılmasının uygun olduğu sonucuna varılmıştır.

Birçok deniz ve tatlı su balığında ovaryum sıvısı döllenme kapasitesi ve sperm motilitesi üzerinde etkilidir (Koya vd., 1993; Lahnsteiner vd., 1995; Rosengrave vd., 2008; İnanan ve Öğretmen, 2015; Ozgur, 2018). Ovaryum sıvısının döllenme üzerindeki bu etkisi bilinmesine rağmen bu etkinin nasıl olduğu ile ilgili çalışmalar halen devam etmektedir. Yapılan çalışmalar ovaryum sıvısının uzaklaştırılmasının döllenme yüzdesinde düşüklük ile sonuçlandırdığını ancak yine de döllenmenin gerçekleştiğini ortaya koymuştur (Stoddard vd., 2006). Bu çalışmalara ilaveten Dil balığı ile yapilan bir çalışmada ovaryum sıvısının döllenme üzerinde herhangi bir etkisinin olmadığı bildirilmiş̧ir (Jia vd., 2015).

$\mathrm{Bu}$ çalışmada, ovaryum sıvısı ile aktive olan spermatozoa' da motilite değerleri yüksek bulunmuş ve buna ilaveten ovaryum sıvısının uzaklaştırılması ile gerçekleştirilen dölleme çalışmasındaki gruplardaki döllenme yüzdesi, ovaryum sıvısının muhafaza edildiği gruplardan daha düşük bulunmuştur. Ancak deneme grupları arasındaki döllenme yüzdesinin farkı kabul edilebilir olarak değerlendirilmiştir. Döllemenin yapıldığı sperm örneklerinde motilite arasında ki istatistiksel fark ise, kullanılan kuluçkahane suyunun sperm motilesini sağlamak için çok efektif olmadığını ancak dölleme solüsyonu olarak kullanıldığında yumurta ve sperm etkileşimine ilaveten yumurtanın kemotaksisi üzerinde etkili olduğu ve ovaryum sıvısının uzaklaştırılmış olmasına rağmen döllemede ovaryum sıvısı kadar yumurtanın kendisinin de kemotaksi sağlayabildiği ve yumurtanın kemoatraktan yardımı ile sperm hücrelerini döllemede kullandığı sonucuna varılmıştır. 


\section{KAYNAKLAR}

Alonzo S.H., Stiver K.A., \& Marsh-Rollo S.E. (2016). Ovarian fluid allows directional cryptic female choice despite external fertilization. Nature Communications, 7, 124-152.

Barannikova I.A., Dyubin V.P., Bayunova L.V., \& Semenkova T.B. (2002). Steroids in the control of reproductive function in fish. Neuroscience and Behavioral physiology, 32(2), 141-148.

Bayunova L.V., Barannikova I.A., Dyubin V.P., Gruslova A.B., Semenkova T.B., \& Trenkler I.V. (2003). Sex steroids concentrations in Russian sturgeon (Acipenser gueldenstaedti) serum and coelomic fluid at final oocyte maturation. Fish Physiology and Biochemistry, 28(1-4), 325-326.

Billard R., \& Cosson M. (1992). Some problems related to the assessment ofsperm motility in freshwater fish. Journal of Experimental Biology, 261, 122-131.

Boryshpolets, S., Kowalski, R. K., Dietrich, G. J., Dzyuba, B., \& Ciereszko, A. (2013). Different computerassisted sperm analysis (CASA) systems highly influence sperm motility parameters. Theriogenology, 80(7), 758-765.

Butts I.A., Johnson K., Wilson C.C., \& Pitcher T.E. (2012). Ovarian fluid enhances sperm velocity based on relatedness in lake trout, Salvelinus namaycush. Theriogenology, 78(9), 2105-2109.

Butts I.A., Prokopchuk G., Kašpar V., Cosson J., \& Pitcher T.E. (2017). Ovarian fluid impacts flagellar beating and biomechanical metrics of sperm between alternative reproductive tactics. Journal of Experimental Biology, 220(12), 2210-2217.

Cosson J. (2004). The ionic and osmotic factors controlling motility of fish spermatozoa. Aquaculture International, 12, 69-85.

Cosson J. (2008). Methods to analyse the movements of the spermatozoa and their flagella. In: Alavi SMH, Cosson J, Coward K, Rafiee G. editors. Fish spermatology. Alpha Sci- ence Ltd, Oxford, pp 63-102.

Cosson J. (2010) Frenetic activation of fish spermatozoa flagella entails short-term motility, portending their precocious decadence. Journal of Fish Biology 76, 240-279.

Çelikkale, M.S. (2002). İçcu Balıkları ve Yetiştiriciliğii. Cilt 1, 3.Baskı, Karadeniz Teknik Üniversitesi Matbaası, Genel Yayın No: 124, Fakülte Yayın No: 2, Trabzon.

Dietrich G.J., Wojtczak M., Słowińska M., Dobosz S., Kuźmiński H., \& Ciereszko A. (2008). Effects of ovarian fluid on motility characteristics of rainbow trout (Oncorhynchus mykiss Walbaum) spermatozoa. Journal of Applied Ichthyology, 24, 503-507.

Diogo P., Soares F., Dinis M.T., \& Cabrita E. (2010). The influence of ovarian fluid on Solea senegalensis sperm motility. Journal of Applied Ichthyology, 26(5), 690-695.

Elofsson H., Van Look K., Borg B., \& Mayer I. (2003). Influence of salinity and ovarian fluid on sperm motility in the fifteen-spined stickleback. Journal of Fish Biology, 63(6), 1429-1438.

Galvano P.M., Johnson K., Wilson C.C., Pitcher T.E., \& Butts I.A. (2013). Ovarian fluid influences sperm performance in lake trout, Salvelinus namaycush. Reproductive biology, 13(2), 172-175.

Golpour A., Akhoundian M., Khara H., Rahbar M., \& Dadras H. (2013). Changes of sperm quality parameters in Caspian roach (Rutilus rutilus caspicus) during spawning migration. Czech Journal of Animal Science, 3, $117-124$.

Hatef A., Niksirat H., \& Alavi S.M.H. (2009). Composition of ovarian fluid in endangered Caspian brown trout, Salmo trutta caspius, and its effects on spermatozoa motility and fertilizing ability compared to freshwater and a saline medium. Fish Physiology and Biochemistry, 35(4), 695-700.

Hirano T., Morisawa M., \& Suzuki K. (1978). Changes in plasma and coelomic fluid composition of the mature salmon (Onchorhynchus keta) during freshwater addition. Comparative Biochemistry and Physiology, A $61,5-8$.

Hunter, J. R., Lo, N. C., \& Leong, R. J. (1985). Batch fecundity in multiple spawning fishes (pp. 67-77). NOAA Technical Report NMFS 36.

İnanan B.E., \& Öğretmen F. (2015). Determination of differences in the biochemical properties of sperm activating and non-activating ovarian fluids and their influences on sperm motility in rainbow trout (Oncorhynchus mykiss). Aquaculture, 448, 539-544.

Jia Y.D., Niu H.X., Meng Z., Liu X.F., \& Lei J.L. (2015). Biochemical composition of the ovarian fluid and its effects on the fertilization capacity of turbot Scophthalmus maximus during the spawning season. Journal of Fish Biology, 86(5), 1612-1620.

Johnson S.L., Villarroel M., Rosengrave P., Carne A., Kleffmann T., Lokman P.M., \& Gemmell N.J. (2014). Proteomic analysis of chinook salmon (Oncorhynchus tshawytscha) ovarian fluid. PloS One, 9(8), e104155.

Kholodnyy V., Gadêlha H., Cosson J., \& Boryshpolets S. (2019). How do freshwater fish sperm find the egg? The physicochemical factors guiding the gamete encounters of externally fertilizing freshwater fish. Reviews in Aquaculture, 1-28. 
Kime D.E., Van Look K.J.W., McAllister B.G., Huyskens G., Rurangwa E., \& Ollevier F. (2001). Computerassisted sperm analysis (CASA) as a tool for monitoring sperm quality in fish. Comparative Biochemistry and Physiology Part C: Toxicology and Pharmacology, 130(4), 425-433.

Koya Y., Munehara H., Takano K., \& Takahashi H. (1993). Effects of extracellular environments on the motility of spermatozoa in several marine sculpins with internal gametic association. Comparative Biochemistry and Physiology Part A: Physiology, 106(1), 25-29.

Lahnsteiner F., Weisman T.R., \& Patzner A. (1995). Composition of the ovarian fluid in 4 salmonid species: Onchorhynchus mykiss, Salmo trutta f lacustris, Salvelinus lacustris, and Hucho hucho. Reproduction Nutrition Development, 35, 465-474.

Lahnsteiner F., Berger B., Weismann T., \& Patzner R.A. (1997). Sperm structure and motility of the freshwater teleost Cottus gobio. Journal of Fish Biology, 50(3), 564-574.

Lahnsteiner F. (2002). The influence of ovarian fluid on the gamete physiology in the Salmonidae. Fish Physiology and Biochemistry, 27(1-2), 49-59.

Lehnert S.J., Butts I.A., Flannery E.W., Peters K.M., Heath D.D., \& Pitcher T.E. (2017). Effects of ovarian fluid and genetic differences on sperm performance and fertilization success of alternative reproductive tactics in Chinook salmon. Journal of Evolutionary Biology, 30(6), 1236-1245.

Lewis J.A., \& Pitcher T.E. (2017). Tactic-specific benefits of polyandry in Chinook salmon Oncorhynchus tshawytscha. Journal of Fish Biology, 90(4), 1244-1256.

Litvak M.K., \& Trippel E.A. (1998). Sperm motility patterns of Atlantic cod (Gadus morhua) in relation to salinity: effects of ovarian fluid and egg presence. Canadian Journal of Fisheries and Aquatic Sciences, 55(8), 1871-1877.

Macfarlane C.P. (2002). Gametic interactions in externally fertilising fishes. Ph.D. Thesis. University of Liverpool, 118 p., UK.

Morisawa, M., \& Yoshida, M. (2005). Activation of motility and chemotaxis in the spermatozoa: From invertebrates to humans. Reproductive Medicine and Biology, 4(2), 101-114.

Ozgur, M. E. (2018). The Effects of Different Sperm Activator Medias on the Velocity and Movement Style Brown Trout (Salmo trutta Linnaeus, 1792) Sperm Cells. Aquaculture Studies, 18(2), 75-78.

Özgür, M. E., Okumuş, F., \& Kocamaz, A. F. (2019). A novel computer assisted sperm analyzer for assessment of spermatozoa motility in fish; BASA-Sperm Aqua. El-Cezeri Journal of Science and Engineering, 6(1), 208-219.

Rakitin A., Ferguson M.M., \& Trippel E.A. (1999a). Spermatocrit and spermatozoa density in Atlantic cod (Gadus morhua): correlation and variation during the spawning season. Aquaculture, 170 (3-4), 349-358.

Rakitin A., Ferguson M.M., \& Trippel E.A. (1999b). Sperm competition and fertilization success in Atlantic cod (Gadus morhua): effect of sire size and condition factor on gamete quality. Canadian Journal of Fisheries and Aquatic Sciences, 56(12), 2315-2323.

Rosengrave P., Taylor H., Montgomerie R., Metcalf V., McBride K., \& Gemmell N.J. (2009). Chemical composition of seminal and ovarian fluids of chinook salmon (Oncorhynchus tshawytscha) and their effects on sperm motility traits. Comparative Biochemistry and Physiology Part A: Molecular and Integrative Physiology, 152(1), 123-129.

Rosengrave P., Montgomerie R., \& Gemmell N. (2016). Cryptic female choice enhances fertilization success and embryo survival in chinook salmon. Proceedings of the Royal Society B: Biological Sciences, 283 (1827), 20160001.

Stoddard J.W., Parsons J.E., \& Nagler J.J. (2006). Early onset of embryonic mortality in sub-fertile families of rainbow trout (Oncorhynchus mykiss). Reproduction, Fertility and Development, 17 (8), 785-790.

Stoss J. (1983). Fish gamete preservation and spermatozoan physiology. Fish physiology, 9B, 305-350.

Turner E., \& Montgomerie R. (2002). Ovarian fluid enhances sperm movement in Arctic charr. Journal of Fish Biology, 60(6), 1570-1579.

Urbach D., Folstad I., \& Rudolfsen G. (2005). Effects of ovarian fluid on sperm velocity in Arctic charr (Salvelinus alpinus). Behavioral Ecology and Sociobiology, 57(5), 438-444.

Wojtczak M., Dietrich G.J., Słowińska M., Dobosz S., Kuźmiński H., \& Ciereszko A. (2007). Ovarian fluid pH enhances motility parameters of rainbow trout (Oncorhynchus mykiss) spermatozoa. Aquaculture, 270(14), 259-264.

Zadmajid V., Myers J.N., Sørensen S.R., \& Butts I.A. (2019). Ovarian fluid and its impacts on spermatozoa performance in fish: a review. Theriogenology. 132, 144-152. 